\title{
Mikroplastikler: Gıdalarda Bulunuşu ve Sağlık Üzerine Etkileri
}

\author{
Selen Akçay ${ }^{1}$, Fatih Törnük ${ }^{2 *}$, Hasan Yetim ${ }^{3}$ \\ 1 Üsküdar Üniversitesi, Sağlık Hizmetleri Meslek Yüksekokulu, Gıda Teknolojisi Programı, İstanbul, Türkiye (ORCID: 0000-0003-3123-3010) \\ ${ }^{2 *}$ Yıldız Teknik Üniversitesi, Kimya-Metalürji Fakültesi, Gıda Mühendisliği Bölümü, İstanbul, Türkiye (ORCID: 0000-0002-7313-0207) \\ ${ }^{3}$ Sabahattin Zaim Üniversitesi, Mühendislik ve Doğa Bilimleri Fakültesi, Gıda Mühendisliği Bölümü, İstanbul, Türkiye (ORCID: 0000-0002-5388-5856)
}

(İlk Geliş Tarihi 22 Nisan 2020 ve Kabul Tarihi 1 Kasım 2020)

(DOI: 10.31590 /ejosat.725259)

ATIF/REFERENCE: Akçay, S., Törnük, F. \& Yetim, H. (2020). Mikroplastikler: Gıdalarda Bulunuşu ve Sağlık Üzerine Etkileri. Avrupa Bilim ve Teknoloji Dergisi, (20), 530-538.

$\ddot{\mathbf{O} z}$

Plastik malzemeler günlük hayatımızın hemen hemen her alanında yer almaktadır. Yaygın kulanımı nedeniyle hayatın vazgeçilmez unsurlarından biri olan plastikler, çevre açısından da günümüzün en büyük kirleticilerinden birisi olarak görülmektedir. Her geçen gün daha da artan plastik kullanımının özellikle okyanuslar ve denizlerde çok ciddi bir kirlilik oluşturduğu bilinmektedir. Plastik kirliliğini oluşturan en önemli iki unsur, endüstriyel faaliyetler ve antropojenik etkilerdir. Çevreye bırakılan tonlarca plastik atık, çevresel koşulların etkisiyle fiziksel olarak küçük parçalara ayrılsa da yüzyıllarca doğada bozunmadan kalmaktadır. Plastiklerin parçalanmaları ile oluşan mikron ve mikron altı boyuttaki bu parçacıklara, mikroplastik adı verilmektedir. Mikroplastikler güncel bir konu olmasının yanı sıra çevre kirliliği oluşturması ve doğal yaşama etkileri nedeniyle son yıllarda giderek daha da büyük bir önem kazanmaktadır. Mikroplastikler günümüzde hem suda yaşayan canlılar ve hem de insan sağlığ insan vücuduna geçişi, cilt teması, solunum ve oral yolla gerçekleşmektedir. Farklı yollarla insan vücuduna giren mikroplastiklerin sağlık üzerine oluşturduğu riskler, hala tam olarak bir netlik kazanamamıştır. Özellikle insanların mikroplastiklerle kontamine olmuş su kaynakları ve gıdaları tüketmeleri sonucu vücuda çoklu mikroplastik alımının gerçekleşmesi muhtemeldir. Su kaynakları ve suda yaşayan canlılarda mikroplastik varlığının belirlenmesi ile ilgili çok sayıda çalışma yapılmıştır. Gıda maddelerinde yapılan sınırlı sayıdaki çalışma ise gıdaların da mikroplastikler içerebileceğini göstermiştir. Gıda maddelerinde mikroplastiklerin bulunuşu; hammadde, gıda üretim aşamaları, ambalajlamada kullanılan plastikler veya havadan kaynaklanabilmektedir. Bu derlemede, mikroplastiklerin oluşumu, yiyecek ve içecekler yoluyla insanlara geçişi ve çevre ve insan sağlığı üzerine etkileri üzerine yapılmış çalışmaların irdelenmesi amaçlanmıştır.

Anahtar Kelimeler: Mikroplastikler, ekosistem, sağlık, gıda zinciri

\section{Microplastics: Effects on Health and Occurence in Foods}

\begin{abstract}
Plastic materials are found in almost every place of the daily life. Plastics, which have become an indispensable item of the human life due to their widespread use, are considered as one of the biggest pollutants of today. It is known that plastic use, which increases day by day, creates a serious pollution problem especially in the oceans and seas. The two most important factors which causes plastic pollution are the industrial activities and anthropogenic effects. Although tons of waste plastic released to the environment are physically crashed by the effect of environmental conditions, they can still remain without degraded in the nature for decades even hundreds of years. These micronic and submicronic particles formed by the decomposition of the plastics are called microplastics. In addition to being a current subject, microplastics have gained great attention or importance in recent years in terms of creating environmental pollution. Microplastics have become a serious threat to both aquatic life and human health. The transition of microplastics to the human body takes place through skin contact, inhalation and oral route. The risks and health effects of the microplastics when taken into the human body by different routes has not been well-clarified yet. It is likely that multiple microplastic uptake into the body would take place as a result of consumption of the contaminated water sources and the foods. Numerous studies have been conducted on the determination of the presence of microplastics in water resources and the aquatic life. However, a limited number of studies on foodstuffs have shown that our foods may also contain microplastics. Microplastic formation in foodstuffs may be resulted from the raw materials,
\end{abstract}

* Yıldız Teknik Üniversitesi, Kimya-Metalürji Fakültesi, Gıda Mühendisliği Bölümü, İstanbul, Türkiye (ORCID: 0000-0002-7313-0207), ftornuk@yildiz.edu.tr 
food production or processing steps and the plastics used in packaging or air. The purpose of this review was to evaluate the effects of microplastics on the environmental pollution and human health, and their presence in the food chain were scrutinized.

Keywords: Microplastic, Ecosystem, Health, Food chain.

\section{Giriş}

Plastikler, tekrar eden çok sayıda monomer zincirinden oluşan ve polimerlerden üretilen malzemelerdir. Plastik üretiminde hammadde olarak çoğunlukla petrol ve doğalgaz kullanılmakta iken henüz küçük bir kısmını teşkil etse bile son yıllarda mısır ve şeker kamışı gibi bitkisel hammaddelerden de plastik üretimi söz konusudur (Tsiropoulos veark., 2015). Ayrıca, dünyada üretilen ham petrolün yalnızca $\% 4$ 'ü plastik üretimi amacıyla kullanılmaktadır (Öztürk, 2005; Yıldıztekin ve ark., 2017).

Farklı hammaddeler kullanılarak elde edilen plastik malzemeler kendilerine özgü özelliklere sahiptirler. Sahip olduğu değişik özellikleri sayesinde tüketici kullanımına pek çok plastik malzeme sunulmaktadır. Bu plastik türleri; düşük yoğunluklu polietilen (LDPE), yüksek yoğunluklu polietilen (HDPE), polietilen tereftalat (PET), polipropilen (PP), polistiren (PS), polivinil klorür (PVC) ve poliamid (PA) olarak sıralanabilir (Waring ve ark., 2018). Plastiklerin özellikleri; üretiminde kullanılan polimerlerin kimyasal ve fiziksel özellikleri, molekül ağırlıkları, kristalinite düzeyleri ve kimyasal kompozisyonları gibi birçok faktörden etkilenebilir. Bu yolla gıda ambalajlamada farklı ürünlerin paketlenmesinde kullanılan ve pek çok amaça hizmet eden plastik malzemeler geliştirilmiştir.

Plastik çağını yaşadığımız bu yüzyılda kimya, malzeme bilimi ve gida zinciri dâhil olmak üzere her alanda plastikler kullanılırken, çağımızın en büyük kirleticileri de plastikler olarak görülmektedir. Basit gıda ambalajlarından sentetik lifler, araba lastikleri, plastik içeren kıyafetler gibi hayatımıza çeşitli şekilde dâhil olmuş plastik malzemeler hava, su, toprak kalitesinde geri dönüşümsüz çevresel problemlere neden olmaktadır (Fonseca ve ark., 2017; Aslan, 2018). Deniz ortamları plastik kirlenmesinden en çok etkilenen yerlerin başında gelmektedir. Çevreye farklı yollarla geçen plastiklerin yağışlar ve akışlar aracılığıyla okyanus yüzeylerinde plastik çöplüğü oluşturduğu bilinmektedir (Yurtsever, 2018; Botterell ve ark., 2019). 1950'li yıllarda 1,7 milyon ton plastik tüketiminden 2015 yilında 322 milyon ton plastik tüketiminin gerçekleştiği dikkate alındığında, rakamların her geçen gün arttığı açık bir şekilde görülmektedir (Fonseca ve ark., 2017).

Türk Gıda Kodeksi gıda ile temas eden plastik malzemeler tebliğinde, özellikle renklendiriciler, yapıştırıcılar, plastikleştirici katkı maddeleri ve bunların gıdaya migrasyonu ile çok katmanlı plastik malzemeler, yapıştırıcılar, kapatma elemanı olarak kullanılan plastik contalar üzerinde durulmuştur. Özellikle küçük çocuk ve bebek gıdaları ile temas halindeki plastik malzemelerde migrasyon limitinin $60 \mathrm{mg} / \mathrm{kg}$ olması yönünde açık bir ibare bulunmaktadır (Türk Gıda Kodeksi, 2019).

Plastiklerin çevre üzerine zararlı etkileri yapılan araştırmalarla ortaya koyulurken, her yıl yaklaşık 4,8-12,7 milyon ton plastiğin deniz ortamına girdiği bildirilmiştir. $\mathrm{Bu}$ duruma petrol türevi plastiklerin biyobozunur olmamaları ve uzun süreli dayanıklılıkları da eklendiğinde insan faaliyetleri sonucunda oluşan plastik kirliliğinin yüzyıllar boyunca devam edeceği tahmin edilmektedir. Bu nedenle plastik; küresel, çevresel ve ekonomik kirleticilerden biri olarak kabul edilmektedir (Botterell ve ark., 2019).

Plastikler malzemelerin zamanla farklı bozunma mekanizmalarıyla kendini oluşturan monomerlere parçalanması ile mikroplastik kavramı ortaya çıkmıştır. Partikül boyutu 1 $\mu$ m'den 5 mm'ye kadar değişen ve farklı çeşit ve oranlarda polimer ve katkı maddelerinden oluşan küçük plastik parçacıklarına "mikroplastik" adı verilmektedir (Fonseca ve ark., 2017; Aslan, 2018; Welle ve Franz, 2018). Mikroplastikler, kaynaklarına göre primer ve sekonder mikroplastikler olarak 2'ye ayrılmaktadır. Primer mikroplastikler, değişik boyutlarda endüstriyel olarak mikroboncuklara verilen isim olup üretim ve taşıma gibi aşamalarda çevreye kontaminant olarak yayılmaktadır (Andrady, 2017). Okyanus ve denizlerdeki asıl mikroplastik kaynağı ise sekonder mikroplastiklerdir (Barnes ve ark., 2009). Bunlar; kullanılmakta olan plastik malzemelerin ve çöplerin çevre koşullarının etkisiyle parçalanması sonucu havaya, toprağa ve denizlere karışırlar (Andrady, 2017). Mikroplastiklerin kara ve denizlerdeki varlığı, son yıllarda güncel hale gelmiş ve yoğun araştırmaların konusu olmuştur (Welle ve Franz, 2018). Bununla birlikte, mikroplastiklerin gıdalardaki varlığı henüz yeni bir araştırma konusu olup bu konuda yapılmış araştırmaların çok sınırlı olduğu görülmektedir. Bu araştırmada, mikroplastiklerin özellikleri, çevre ve sağlık üzerindeki olumsuz etkileri ve gıdalarda bulunuşu hakkında yapılmış olan çalışmalar derlenmiştir.

\section{Mikroplastiklerin Özellikleri, Çevre ve Sağlık Üzerindeki Etkileri}

Mikroplastikler, plastik kaynaklı kirleticiler arasında son y1llarda en fazla dikkati çeken konu olmuştur. Mikroplastikler morfolojik olarak amorf, küresel ve uzun lif formu gibi pek çok şekilde bulunabilirler (Yurtsever, 2015). Mikroplastikler ayrıca, boyut, komposizyon, ağırlık, fiziksel ve kimyasal özellikleri gibi pek çok açıdan da farklılık göstermektedir. Literatüre bakıldığında mikroplastiklerin boyutları ile ilgili bir fikir birliği görülmemektedir. Saha çalışmalarında, yüzey suyunundan örnek alırken kullanılan ve plaj kumunu örneklemede kullanılan elekler, alt partikül boyutunu belirlemektedir (Law ve ark., 2010; Hidalgo-Ruz ve ark., 2012). Genellikle $330 \mu \mathrm{m}$ delik çapına sahip ağlarla küçük çaplı mikroplastiklerin tutulamaması, örneklenen mikroplastiklerin partikül boyutunun yüksek çıkmasına neden olmaktadır (Song ve ark., 2014). Deniz ortamındaki mikroplastikler tipik olarak topaklar, fragmanlar veya lifler halinde bulunmaktadır (Smith ve ark., 2018).

Mikroplastiklerin boyutları konusunda 2016 yılında GESAMP (The Joint Group of Experts on the Scientific Aspects of Marine Environmental Protection), Tablo 1'de görüldüğü gibi bir boyut sınıflandırması yayınlamıştır (GESAMP, 2015). 
Tablo 1. Çevrede yer alan plastik atıkların boyut dağılımları (GESAMP, 2016).

\begin{tabular}{l|c|c|c}
\hline Sınıf & Boyut dağılımı & Görülebilirlik & Teknik \\
\hline Makroplastik & $100-2,5 \mathrm{~cm}$ & Çılak gözle & Görsel sayım \\
\hline Mezoplastik & $2,5-0,1 \mathrm{~cm}(1000 \mu \mathrm{m})$ & Çıplak gözle veya optik mikroskopla & Neuston ağları ve elekler \\
\hline Mikroplastik & $0,1 \mathrm{~cm}-1 \mu \mathrm{m}$ & Optik mikroskopla & $<1 \mu \mathrm{m}$ ayırabillen mikrofiltreler \\
\hline Nanoplastik & $<1 \mu \mathrm{m}$ & Elektron mikroskobuyla & Nanofiltreler \\
\hline
\end{tabular}

Tablo 1'de görüldüğü gibi, farklı boyutsal özelliklere sahip olan plastiklerden büyük boyutlu olanları çıplak gözle görülebilmekte iken, boyut küçüldükçe tespiti için mikroskoplara ihtiyaç duyulmaktadır.

\subsection{Mikroplastiklerin Çevreye Dağılımı ve Etkileri}

1960 'l y yllardan beri, plastik üretimi her y1l \% 8,7 oranında büyüme göstererek küresel bir endüstri halini almıştır. Her yıl yaklaşık 8 milyon ton plastiğin okyanuslara karıştığ edilmektedir. Ayrıca şu anda 5,25 trilyon plastik partikülün okyanus yüzey sularında bulunduğu ifade edilmektedir (Smith ve ark., 2018). Yapılan araştırmalar, plastiklerin farklı yollarla aşınması sonucu oluşan gözle görülemeyen boyutlardaki kirlilik unsuru mikroplastiklerin su ekosisteminde gitgide daha fazla yoğunlaştığı ve sucul biyota için ciddi bir toksikolojik risk faktörü olduğu gerçeğini ortaya koymuştur (Alimba ve Faggio, 2019).

Karasal ve sucul ekosistemlere dahil olan plastik polimerler güneş 1şı̆̆g, dalga gibi doğal etkiler ile mikroplastiklere parçalanmaktadır. Plastiklerin bozunma derecesi; polimer tipi, sıcaklık, 1şınlama ve $\mathrm{pH}$ gibi çevresel faktörlerden etkilenmektedir (Akbay ve Özdemir, 2016; Smith ve ark., 2018). Pek çok deniz memelisi, omurgasızlar, balık yiyen kuşlar ve balıklar bu mikroplastikleri yutmaktadır. Bu plastik parçacıklar karkas diseksiyonu ve özellikle sindirim sisteminde görülmektedir. Mikro- ve nano plastik parçacıkların ayrıca dolaşım sistemi yoluyla çevre doku ve organlara geçiş yapabildiği de belirlenmiştir (Lusher ve ark., 2017; Smith ve ark., 2018).
Mevcut koşullarda mikroplastiklerin çevrede kalıcı bir kirletici olma potansiyeli ve sürekli ekosistemde birikim gösterdiği bilinmektedir. İnsanlar için oldukça endişe verici olan bu durum özellikle belirli olmayan verilerle birlikte daha da karmaşık bir hal almıştır (Esmeray ve Armutçu, 2020).

\subsection{Mikroplastiklerin İnsan Sağlı̆̆ı Üzerindeki Etkileri}

Mikroplastiklerin insan sağlığı üzerine etkileri incelendiğinde, yapılan çalışmalar günümüzde maruz kaldığımız pek çok kimyasal maddeye dair olsa da, mikroplastiklerin çevreyi kirletme potansiyeli ve besin zincirine dahil olması ile ilgili çok az sayıda çalışma bulunmaktadır. Bunun yanı sıra mikroplastikler ve bunlarla ilişkili kimyasal bileşenlerin deniz ürünleri aracıllğıyla insanlara geçişi ve tüketici sağlığına olan etkileri üzerine henüz yeterli çalışma bulunmamaktadır (Carbery ve ark., 2018).

Plastik materyallerin farklı koşullarda parçalanması sonucu insan vücuduna etki mekanizması ve potansiyeli partikül boyutu ve maruz kalma konsantrasyonu ile ilişsilidir. Tablo 2'de mikrove nano plastik partiküllerinin memeli canlılarda epitel boyunca transkolasyon durumu gösterilmiştir. Partikül boyutunun $150 \mu \mathrm{m}$ ve daha küçük olması oluşan partikülün mukozal bariyerden geçebileceğini gösterirken, $1,5 \mu \mathrm{m}$ 'den daha küçük partikül boyutları daha derin dokulara ulaşabilmektedir (Lusher ve ark., 2017).

Tablo 2. Mikroplastik ve nanoplastik partikül boyutunun memeli canlllarda absorbsiyon durumu (Lusher ve ark., 2017)

\begin{tabular}{l|l}
\hline Mikroplastik (0,1 -5000 $\boldsymbol{\mu m})$ & Nanoplastik (1-100 nm) \\
\hline$>150 \mu \mathrm{m}$ - Absorbsiyon bulunmamaktadır. & $\begin{array}{l}\leq 100 \mathrm{~nm} \text {-Tüm organlara erişim bulunmak ile birlikte kan-beyin hücrelerine } \\
\text { translokasyon ve plasental bariyerden geçiş }\end{array}$ \\
\hline$<150 \mu \mathrm{m}-\leq \% 0,3$ oranında lenf dokuda emilim & Absorbsiyon oranı \% 7 'nin üzerinde \\
\hline$=110 \mu \mathrm{m}-$ Portal damarda emilim $\quad$ Organlara erişim & \\
\hline$\leq 20 \mu \mathrm{m}$ & \\
$(\leq 20000 \mathrm{~nm})$ & \\
\hline
\end{tabular}

İnsanlar için mikroplastiklere maruz kalma durumu çok yönlüdür. Bunlar genel olarak; inhalasyon (solunan havadaki mikroplastik varlığı; şehir tozu, toz sentetik kauçuk materyaller vb.), oral yol ve cilt teması (sentetik tekstil ürünleri) olarak sınıflandırılabilir. Bunun yanı sıra kirlenmiş deniz ürünleri tüketimi, diğer yiyecek türleri ve mikroplastik ile kirlenmiş içme sularının tüketimi, gastrointestinal sisteme partiküllerin direk geçiş yolunu oluşturmaktadır. İnsan derisi mikroplastik ve diğer kirleticilerin bu süreçte vücuda girişini engelleme yeteneğine sahipse de açık yaralar, ter bezleri, saç derisi gibi olası yollarından mikroplastik geçişi ortaya çıkmaktadır (Torre, 2019). Mikroplastikler pek çok canlıda farklı boyutlarda dolaşım sistemine dâhil olabilmektedirler. Yapılan çalışmalarda mikroplastiklerin insanlar (parçacık boyutu 0,2-150 $\mu \mathrm{m}$ ), kemirgenler (30-40 $\mu \mathrm{m})$, tavşanlar (0,1-10 $\mu \mathrm{m})$ ve köpeklerde (3$100 \mu \mathrm{m})$ lenf ve dolaşım sistemine translokasyon kapasitesine sahip olduğu bildirilmektedir (Peixoto ve ark., 2019).

Stock ve ark. (2019) tarafindan yapılan çalışmada, polistiren (PS) mikroplastik parçacıklarının in vitro olarak insan hücrelerine ve in vivo olarak kemirgenlere geçişi incelenmiş ve PS partiküllerinin immun sistem üzerine etkileri araştırılmıştır. $\mathrm{Bu}$ çalışma sonucunda in vitro koşullarda $1 \mu \mathrm{m}, 4 \mu \mathrm{m}$ ve $10 \mu \mathrm{m}$ büyüklügüündeki mikroplastik parçacıklar seçilen deneysel koşullarda oral yolla maruz kalmanın memeliler için akut sağlık riskleri oluşturmadığı ifade edilmiştir. Hesler ve ark. (2019) tarafindan yapılan bir başka çalışmada ise $50 \mathrm{~nm}$ ve $0,5 \mu \mathrm{m}$ büyüklügüündeki karboksile PS partiküllerinin insan intestinal ve plesantal hücrelerinden geçişi incelenmiştir. İn vitro modellerde 
hem nanoplastik hem de mikroplastiklere maruz kalındığı ve hücre içine geçişin gerçekleştiği, bununla birlikte bu geçişin sitotoksisiteye veya translokasyona yol açmadığı sonucuna varılmıştır.

20. yüzyılın ortalarında kullanımına başlandığından beri plastik malzemeler sağlıktan gıda güvenliğine, elektronikten otomotiv sektörüne kadar hemen her alanda kullanılmaktadır. $\mathrm{Bu}$ süreçte hayata bu kadar dahil olan plastik malzemelerin tehlike oluşturması ve dolaylı yollardan insan sağlığına olan etkileri büyük bir tartışma konusu olmuştur. Plastik malzemeler içerisinde

\section{Mikroplastiklerin Gidalarda Bulunuşu \\ 3.1. Kara ve Deniz Canlılarında Mikroplastiklerin Varlığı}

Mikroplastiklerin yaygın dağılım gösterdiği ortamlar su ve karasal ekosistemlerdir. Bu maddelerin karasal ortama salınması; diş macunu, temizlik maddeleri ve tekstil elyafları gibi kişisel bakım ürünleri ve boyalar ile lastik gibi malzemeler yoluyla meydana gelmektedir. Okyanuslardaki mikroplastik kirliliğinin yanı sıra deniz ürünlerinde, bira, bal, sofra tuzu, şişelenmiş maden suları gibi yiyecek ve içeceklerde mikroplastik varlığına rastlanmıştır (EFSA, 2016); Welle ve Franz, 2018). Tek bir plastik malzemenin zamanla parçalanarak milyonlarca mikroplastiğe dönüştüğü dünyamızda 1990'lı yıllardan beri 140.000'den fazla deniz hayvanının mikroplastikleri yutarak öldükleri raporlanmıştır (Yurtsever, 2015). Özellikle bu plastiklerin parçalanmasıyla oluşan mikroplastiklerin çevreyi, okyanusları ve gıdalarımızı kirletmesinin yanı sıra gözle görülemeyen plastik partiküllere maruz kalma durumu bireylerde bir farkındalık oluşturmuştur. (Aydın ve ark., 2019).

Oluşan farkındalık durumu ile birlikte tüketiciler plastik tüketimine dikkat etseler de plastiğin gida sistemlerinde kullanımının kısa ve uzun vadeli etkilere sahip olacağ düşünülmektedir. Örneğin, tarımda kullanılan malç kısa vadede verimliliği arttırsa da uzun vadede toprak mikrobiyotasını ve bitki büyümesini olumsuz etkileyebilmektedir (Rustagi ve ark., 2011;

bulunan farklı kimyasal maddelerin pek çoğunun insan kanı, idrarı ve anne sütünde bulunduğu ve insan sağlığı üzerinde potansiyel bir sağlık tehlikesi oluşturduğu belirtilmiştir (Rist ve ark., 2018). Son yıllarda nano- ve mikroplastiklerin de insan sağlığı üzerindeki etkileri değerlendirilmeye başlanmış ancak bu süreçte mikroplastiklerle ilgili yeterli araştırma olmadığından dolayı insanların gıda aracılığıyla ne kadar bir mikroplastik konsantrasyonuna maruz kaldığı bilinmemektedir. Düzenli kabuklu deniz hayvanı tüketen bireylerin yılda yaklaşık 11.000 adet plastik mikro- ve/veya nanoplastik tükettiği tahmin edilmektedir (Lusher ve ark., 2017; Smith ve ark., 2018).

gerekirse, plastik bir alışveriş çantası yaklaşık 20 yıl, strafor bir bardak 50 yıl, plastik bir şise ise 450 yılda bozunmaktadır. Buradan yola çıkarak gıda sistemlerinde kullanılmaya devam eden plastiklerin işlevlerini yitirdikten sonra da gıda, çevre ve insan sağlığına etkilerinin devam edeceği anlamı çıkartılabilir (Yates ve ark., 2019).

Deniz ürünlerinde mikroplastik varlığı bilinen bir gerçek olmasıyla birlikte gıda güvenliğini tehlikeye atan en önemli unsurdur. Deniz canlıları mikroplastikleri yuttuktan sonra enzimatik aktivite ile parçalayamaz ve bu plastikler canlının gastrointestinal sisteminde varlığını devam ettirirler. Ayrıca bağırsak kanalında kalan mikroplastik partikülleri kanalı bloke eder ve besin sindiriminin azalmasına yol açar. Denizlerde yaşayan mikroalglerin de mikro- ve nanoplastiklerin varlığından etkilendiği ve bu organizmalardaki mikroplastik varlığının canlının fotosentetik aktivitesi üzerine düşüşe yol açtığ1 bildirilmiştir (Sjollema ve ark., 2016; Torre, 2019).

Denizlerde yaşayan canlılardaki mikroplastik varlığına yönelik çeşitli araştırmalar yapılmıştır. $\mathrm{Bu}$ araştırmalardan bir kısmı, Tablo 3'de verilmiştir. Tablo 3'de verilmiştir. Bu çalışmalar, deniz canlılarının ne derece yoğun bir mikroplastik maruziyetine maruz kaldıklarını ve riskin boyutunu gösterse de bu birikimin ne kadar sürede gerçekleştiği ve insanların sağlığ açısından tehlikenin boyutu hakkında fikir vermemektedir ve mevcut bulgular henüz varsayım düzeyindedir (Rist ve ark., 2018).

Yates ve ark., 2019). Bu süreçte farklı plastik materyallerin biyolojik bozunma süreleri için tahmini süre örnekleri vermek

Tablo 3. Deniz canlılarında mikroplastik varlı̆̆ üzerine çalışmalar

\begin{tabular}{|c|c|c|c|c|c|}
\hline Örnek & $\begin{array}{ll}\begin{array}{l}\text { Ortalama } \\
\text { İçeriği }\end{array} & \text { Mikroplastik } \\
\end{array}$ & $\begin{array}{l}\text { Mikroplastik } \\
\text { boyutu }\end{array}$ & $\begin{array}{l}\text { Hâkim } \quad \text { Mikroplastik } \\
\text { Türüi }\end{array}$ & Analiz Metodu & Referans \\
\hline $\begin{array}{l}193 \text { balık ve } 136 \text { kabuklu } \\
\text { deniz hayvanına ait solunum } \\
\text { ve gastrointestinal sistem }\end{array}$ & $\begin{array}{c}\text { Solunum sistemi } \\
(0,77 \pm 1,25) \text { adet } / \text { sistem; } \\
\text { gastrointestinal sistem } \\
(0,52 \pm 0,90) \text { adet } / \text { sistem }\end{array}$ & $\begin{array}{c}\text { Solunum sistemi } \\
(655,39 \pm 753,77 \\
\mu \mathrm{m}) ; \text { gastrointestinal } \\
\text { sistem } \\
(727,03 \pm 1148,22 \\
\mu \mathrm{m})\end{array}$ & $\begin{array}{l}\text { PE, PET, PP, PS, PVC, } \\
\text { Naylon, Tripolimer, } \\
\text { Akrilik, Kopolimer }\end{array}$ & FT-IR spektroskopisi & $\begin{array}{l}\text { Zhang ve ark., } \\
2019\end{array}$ \\
\hline $\begin{array}{l}212 \text { balık türü ( } 72 \text { köpek } \\
\text { balığı, } 12 \text { barlam balığı, } 128 \\
\text { kırmızı kefal) }\end{array}$ & $1,56 \pm 0,5$ adet $/ \mathrm{bal} 1 \mathrm{k}$ & $0,38-3,1 \mathrm{~mm}$ & - & Spektroskopik görüntüleme & $\begin{array}{l}\text { Bellas ve ark., } \\
2016\end{array}$ \\
\hline $\begin{array}{l}26 \text { türe ait } 178 \text { balık } \\
\text { örneğinin gastrointestinal } \\
\text { bölgesi }\end{array}$ & $\begin{array}{l}\text { Örneklerin \%26'sında } \\
\text { mikroplastik varlığı }\end{array}$ & $2,39 \pm 0,28 \mathrm{~mm}$ & $\begin{array}{l}\text { PP, PE PS, PVC, PAN } \\
\text { poliakrilonitril }\end{array}$ & $\begin{array}{c}\text { Binoküler } \\
\text { steremikroskopik/FTIR ile } \\
\text { görüntüleme }\end{array}$ & $\begin{array}{c}\text { Baalkhuyur } \\
\text { ve ark., } 2019\end{array}$ \\
\hline $\begin{array}{l}15 \text { türe ait } 4389 \text { adet balık } \\
\text { midesi }\end{array}$ & $\begin{array}{c}0,01-0,17 \text { lif grubu/adet } \\
\text { balık }\end{array}$ & - & $\begin{array}{c}\text { PE, PMMA, PP, PS, } \\
\text { PET, PVC, SA ve diğer } \\
\text { bilinmeyen plastik türleri }\end{array}$ & $\begin{array}{l}\text { Mikroskop altında } \\
\text { gözlemleme/FT-IR } \\
\text { spektroskopisi ile } \\
\text { görüntüleme }\end{array}$ & $\begin{array}{l}\text { Kühn ve ark., } \\
2019\end{array}$ \\
\hline
\end{tabular}

PE: Polietilen; PS: Polistiren; PP: Polipropilen; PET: Polietilen tereftalat; PVC: Polivinilklorür, PMMA: Polimetilmetakrilat; PAN: Poliakrilonitril; SA: Stiren akrilat 
Tablo 3 incelendiğinde, mikroplastik kirliliğinden deniz canlılarının oldukça önemli derecede etkilendiği görülmektedir. Zhang ve ark. (2019) tarafından yapılan çalışmada, balıkların incelenen iki dokusunda (solunum ve gastrointestinal sistem) farklı plastik türü, boyut ve oranda mikroplastik bulunmuştur. $\mathrm{Bu}$ durum nedeniyle deniz canlıları kaynaklı mikroplastik geçişinin kontrol altına alınması gerekliliği üzerinde durulmuştur. Özellikle deniz canlıları üzerine yapılan çalışmalar gastroinstestinal sistem üzerine yoğunlaşmakla birlikte diğer doku ve organlardaki maruziyet durumunun incelenmesi gerekmektedir. Yapilan çalışmalardan anlaşılacağı gibi özellikle deniz canlılarının tüketimiyle insanların da mikroplastik kontaminasyonuna maruz kalacağ 1 açık bir şekilde ifade edilmektedir. Ayrıca araştırmalar sonucunda belirlenen plastik türlerinin büyük bir çoğunluğu insan tüketimine en fazla sunulan polimerlerdir. Bu durum çevrede ve gıda zincirinde oluşan mikroplastik kirliliğinin endüstriyel faaliyetler ve tüketici kaynaklı olduğunu da göstermektedir.

Çin'de yürütülen bir çalışmada 9 ayrı ticari çiftlikten alınan kabuklu hayvan örneklerindeki mikroplastik varlığ 1 araştırılmış ve alınan çift kabukluların tamamında mikroplastik varlığına rastlanmıştır. Mikroplastiklerin çoklu lifler, fragmanlar ve topak halinde bulundukları tespit edilmiştir. Ürünlerde ortalama toplam mikroplastik içeriği 2,1-10,5 partikül/g olarak belirlenmiştir. En çok kirlilik Scapharca subcrenata isimli kabuklu deniz hayvanında 10,5 partikül/g olarak bulunmuştur (Li ve ark., 2015).

Johnson ve ark. (2011) yapılan çalışmada, mavi yengeçlerin yuttuğu plastikler solunum fonksiyonunu etkilemiş bağışıklık sistemi üzerine ciddi durumlar meydana getirmiştir. Japon pirinç balıkları üzerine yapılan bir çalışmada, balıkların mikroplastik tüketimi ile karaciğerinde iltihaplanma gerçekleşmiştir (Lwanga ve ark., 2017). 186 deniz kuşu türünün incelendiği bir çalışmada ise deniz kuşlarında mikroplastikten kaynaklanan bağırsak tıkanıklığı durumu ve toksinler oluşmuştur (Wilcox ve ark., 2015).

Van Cauwenberghe ve Janssen (2014)'ın iki farklı çift kabuklu yumuşakçadaki mikroplastik varlığı üzerine yaptıkları çalışmada, Mytilus edulis örneğinde ortalama mikroplastik varlığ 1 0,36 $\pm 0,07$ partikül/g iken, Crassostrea gigas örneğinde değerler $0,47 \pm 0,16$ partikül/g olarak tespit edilmiştir. Ayrıca çalışmacılar alınan sonuçlar üzerinden tahmini olarak Avrupa'da insanların kabuklu deniz hayvanlarının tüketiminden yılda 11.000 mikroplastik partiküle, yumuşakça tüketiminden dolayı ise yılda 1800 partiküle maruz kalınacağı bildirilmiştir.

Huerta lwanga ve ark. (2017), karasal hayvanlardaki mikroplastik varlığı üzerinde bir çalışma yürütmüştür. Toprak, tavuk dışkısı, toprak solucanları, yemler ve taşlıklardan (insan tüketimine sunulan) alınan örneklerin mikroplastik içeriği incelenmiştir. Çalışmada 100 farklı toprak örneği (50 g), 2 farklı tavuk dişkısı $(10 \mathrm{~g})$ incelenmiştir. Ayrıca ev bahçelerinden rastgele seçimle 5-8 aylık tavuklarda çalışmada kullanılmak üzere seçilmiştir. Toprak örneklerinde $0,87 \pm 1,9 \mathrm{parçac} / \mathrm{k} / \mathrm{g}$ mikroplastik bulunurken, toprak solucanlarında $1,8 \pm 28,8 \mathrm{parçacık/g}$, tavuk dışkısında $82,3 \pm 129,8$ parçacık/g tavuk taşlıklarında ise $10,2 \pm 13,8$ parçacık/g mikroplastik içeriğine rastlanmıştır. Yemlerde ise mikroplastik bulunamamıştır. Bu çalışmada elde edilen veriler mikro ve makroplastiklerin karasal gida zincirine de girebileceğini göstermiştir.

\subsection{Gıda Maddelerinde Mikroplastik Varlığı}

Mikroplastiklerin insanlar tarafından tüketilen deniz canlıları ve diğer sucul hayvanların vücutlarında biriktiği belirlenmiş olmakla birlikte, işlenmiş ve/veya ambalajlanmış gıda maddelerinde de mikroplastiklerin bulunabileceğine yönelik iddialara ortaya atılmaktadır. Gıdalardaki olası mikroplastik varlığının genellikle hammadde, üretim aşamaları veya paketleme sırasında kullanılan plastik ambalaj materyallerinden veya ürünün tüketimi esnasında havadan kaynaklanabileceği düşünülmektedir (Yurtsever, 2019).

Mevcut gida üretim sisteminde, ambalaj materyali olarak en fazla kullanılan malzemeler plastiklerdir. Plastiklerin gida sanayindeki yaygın kullanımı sonucu besin zincirine mikroplastiklerin dahil olması ve insanların maruziyet durumunun artış gösterdiği düşünülmektedir (Van Raamsdonk ve ark., 2020). Yapılan çalışmalarda tek kullanımlık plastik bardaklardan Acrylonitrile maddesi geçişinin kanserojenik olduğu, polikarbonat plastikler, plastik tabak-çatal gibi malzemeler, cam kapların kapakları ve alüminyum konserve kutuların iç kaplamalarından bisfenol A geçişinin gögüs kanseri, prostat kanseri, obezite, diyabet gibi hastalıklara neden olduğu, deterjanlar ve gıda ambalajlarından ftalat geçişi olduğu ve bu geçişin üreme ve sinir sistemi üzerine etkili olduğu, köpük tabak, bardak, sandviç kaplarından stiren(vinil benzen olarak da bilinir) geçişinin kanserojenik etkileri olduğu görülmüştür (Rustagi ve ark., 2011).

Gıdalarda mikroplastik varlığını tespit etmek için Tablo 4'de görüldüğü gibi, Diseksiyon mikroskobu, SEM, FTIR ve Raman Spektroskopisi gibi yöntemler kullanılmaktadır. Diseksiyon mikroskobu, mikroplastik örnekleri boyutlarına ve şekillerine (lif, küresel, granüler, film vs.) göre sinıflandırma ve sayımında kullanılırken, SEM/EDS analizi, mikroplastik partiküllerin elemental kompozisyonunu belirlemede kullanılmaktadır (Erıksen vd., 2013). FTIR (fourier transform infrared) spektroskopisi, filtre üzerinde kalan mikroplastiklerin doğrudan analiz edilmesini mümkün kılan bir teknik olup (Kappler vd., 2016). FTIR ile karbon içeren polimerlerin kolayca tespit edilebildiği belirlenmiştir (Shım vd., 2017). RAMAN spektroskopisi de FTIR gibi, 1şık ile maddenin etkileşimi sonucu maddenin moleküllerindeki titreşimler vasıtasıyla kimyasal ve moleküler yapısın aydınlatılmasında kullanılan yaygın bir tekniktir (Oßmann vd., 2018).

Gıdalarda mikroplastik varlığı ile ilgili çok fazla çalışma olmasa da yapılan bazı çalışmalar deniz canlıları (balık, karides, kabuklular vb.), bira, bal ve sofra tuzunda mikroplastik varlığını göstermektedir (EFSA, 2016). Çalışmalarda deniz ürünlerinde mikroplastik kirliliği ile gıda güvenliği arasında ciddi bir bağlantı kurulsa da mirkroplastiklerin gıda sağlığı ve güvenliğini ne ölçüde riske ettiği üzerinde henüz oldukça sınırlı bilgi bulunmaktadır (Torre, 2019). Tablo 4'te farklı gıda örneklerinde mikroplastik varlığı üzerine yapılmış çalışmalar verilmiştir. 
European Journal of Science and Technology

Tablo 4. Farklı gıda örneklerinde mikroplastik varlığı üzerine araştırmalar

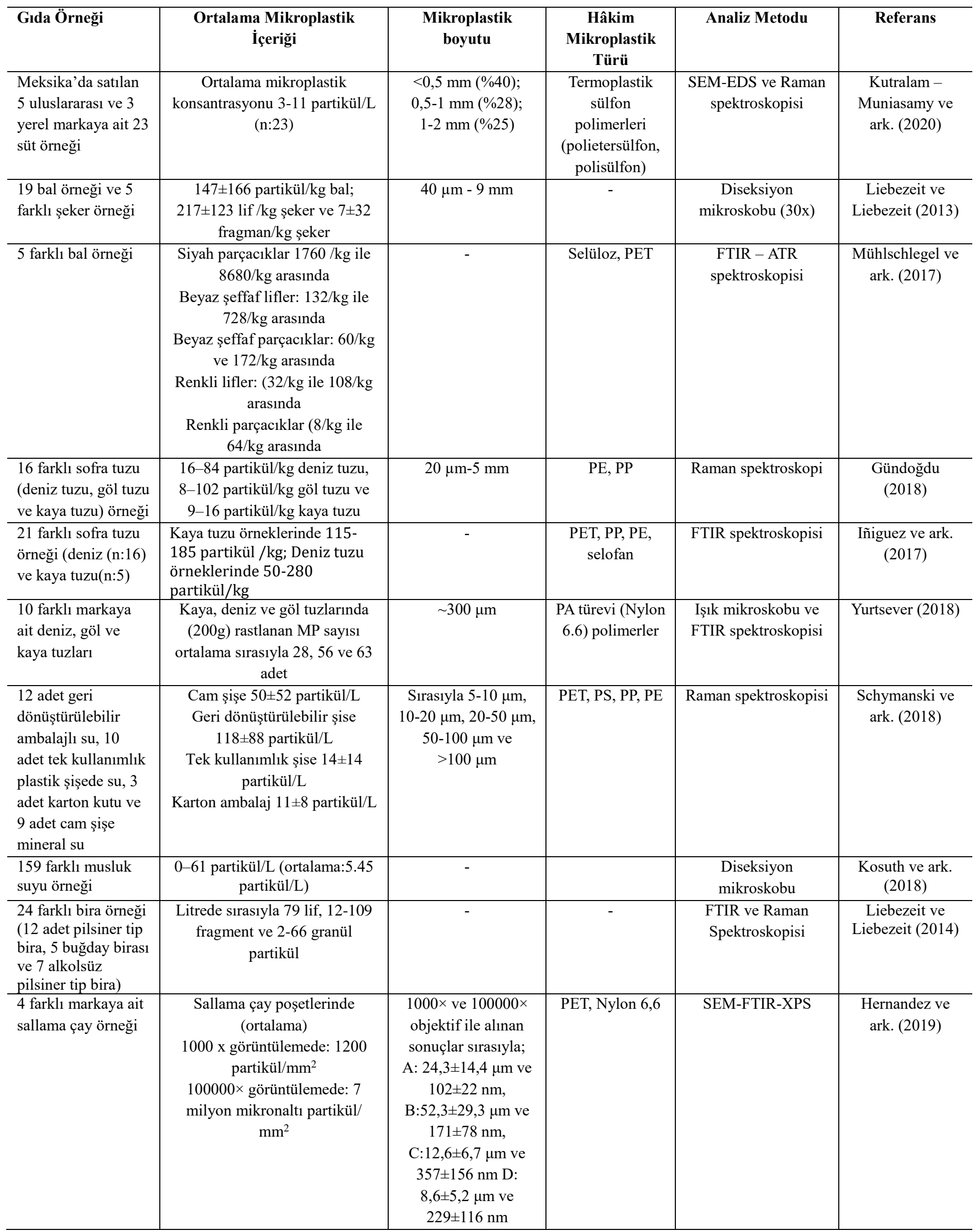




\begin{tabular}{|c|c|c|c|c|c|}
\hline $\begin{array}{l}20 \text { farklı markaya } \\
\text { ait konserve } \\
\text { sardalya ve çaça } \\
\text { balığı örneği }\end{array}$ & $\begin{array}{c}4 \text { farklı markaya ait örnekte 1-3 } \\
\text { parçaçık/ ürün } \\
\text { Dolgu sıvısında plastik partikül } \\
\text { bulunmamıştır. }\end{array}$ & $\begin{array}{l}\text { Ortalama partikül } \\
\text { boyutu } \\
1149 \pm 936 \mu \mathrm{m}\end{array}$ & PP ve PET & $\begin{array}{l}\text { Stereomikroskop, } \\
\text { Raman } \\
\text { spektroskopisi, Enerji } \\
\text { Dağllımlı X-Işı1ı } \\
\text { Spektroskopisi }\end{array}$ & $\begin{array}{l}\text { Karami ve ark. } \\
\text { (2018); Toussaint } \\
\text { ve ark. (2019) }\end{array}$ \\
\hline $\begin{array}{l}4 \text { firmaya ait tavuk } \\
\text { eti örneği }\end{array}$ & $4,0-18,7$ adet $/ \mathrm{kg}$ et & - & XPS & $\begin{array}{c}\text { Diseksiyon } \\
\text { mikroskobu, FTIR } \\
\end{array}$ & $\begin{array}{l}\text { Kedziersk1 ve } \\
\text { ark. }(2020)\end{array}$ \\
\hline $\begin{array}{l}57 \text { içecek örneği ( } \\
19 \text { yumuşak içecek; } \\
8 \text { enerji içeceği, } 4 \\
\text { soğuk çay ve } 26 \\
\text { bira) }\end{array}$ & Ortalama $28 \pm 5,29$ partikül/L & $\begin{array}{l}\text { Ortalama partikül } \\
\text { boyutu } 0.1-3 \mathrm{~mm}\end{array}$ & PA, PEA, PET & $\begin{array}{c}\text { SEM, Raman } \\
\text { spektroskopisi }\end{array}$ & $\begin{array}{l}\text { Shruti ve ark. } \\
\quad(2020)\end{array}$ \\
\hline $\begin{array}{l}5 \text { farklı satıcıdan } \\
\text { temin edilen } 317 \\
\text { midye dolma örneği }\end{array}$ & Ortalam $0.6 \pm 0.1 \mathrm{MP} /$ midye & $\begin{array}{c}\text { Ortalama partikül } \\
\text { boyutu } 1.7 \pm 0.1 \mathrm{~mm}\end{array}$ & $\begin{array}{l}\text { PE, PP ve } \\
\text { selüloz }\end{array}$ & Raman spektroskopisi & $\begin{array}{l}\text { Gündoğdu ve } \\
\text { ark. (2020) }\end{array}$ \\
\hline
\end{tabular}

PE: Polietilen; PS: Polistiren; PP: Polipropilen; PET: Polietilen tereftalat; PVC: Polivinilklorür; XPS: Ekstrüde polistiren, PA:

Poliamid PEA: Poli (ester-amid)

Tablo 4 incelendiğinde, yapılan çalışmalarda mikroplastiklerin gıda zincirine farklı kaynaklardan bulaşabildiği ve gidalar aracılığıyla insan vücuduna mikroplastik kontaminasyonu gerçekleşebileceği görülmektedir. İnsan beslenmesinde önemli bir yere sahip olan süt örnekleri üzerine Kutralam-Muniasamy ve ark. (2020) tarafindan yapilan çalışmada, 23 örneğin hepsinde mikroplastik varlığına rastlanırken bu kirliliğin temel nedenlerinin süt alımı sırasında kullanılan plastik boru malzemeler ve endüstriyel proses basamakları olabileceği üzerinde durulmuştur. Ayrıca çalışmada sadece süt değil kirliliğin boyutlarının gözlemlenebilmesi için süt ve süt ürünlerinde de analizlerin gerçekleştirilmesi gereğinin önemi de vurgulanmıştır. Liebezeit ve Liebezeit (2013) tarafından bal ve şeker örneklerinin incelendiği çalışmada, partikül miktarının hem hammaddenin doğal bir kaynak olmasından hemde proses basamakları sirasından havadan bir kontaminasyondan kaynaklanacağı düşünülmüştür. Mühlschlegel ve ark. (2017) tarafından bal örneklerinin incelendiği çalışmada, balın çevresel kaynaklı materyallerden mikroplastik kontaminasyonuna maruz kaldığı gösterilirken, özellikle dumanlama sırasında kullanılan doğal malzemeler ile otların mikroplastik kirliliğine neden olacağı ve proses aşamasında dumanlama faaliyetinin önemine dikkat çekilmiştir. Ayrıca balın viskoz ve yapışkan bir sıvı olmasından dolayı toz, lif ve mikroplastik partiküllerini kolayca absorbe edeceğinin üzerinde de durulmuştur.

Schymanski ve ark. (2018) tarafindan mineralli sularda yapılan çalışmada, en büyük mikroplastik kirliliği geri dönüştürülebilir şişelerde görülmüştür. Bu kirliliğe yol açan temel etmenin polyester ve polipropilenden yapılan şişelerde meydana gelen potansiyel bir aşınma sonucu gerçekleşen migrasyon ile ilişkili olabileceği öngörülmüştür. Kosuth ve ark. (2018) farklı ülkelere ait musluk sularını incelemiş ve örneklerin yaklaşık $\% 81$ 'inde mikroplastik kirliliğine rastlamıştır. Kirlilik üzerine en etkili faktörün antropojenik faaliyetler olduğunu belirtmiştir. Farklı kaynaklardan elde edilen tuz örneklerinin incelendiği çalımalarda, sucul sistemlerden elde edilen tuzlarda ciddi bir mikroplastik kirliliğine rastlanmıştır. Türkiye'de yürütülen çalışmalarda, özelikle göllerden ve denizlerden elde edilen sofralık tuzlarda görülen ciddi mikroplastik kirliliğinin farklı deşerjlardan beslenen göl ve denizlerimizde antropojenik aktiviteler sonucu oluşan plastik kirliliğinin bir göstergesi olduğu üzerinde durulmuştur. Konserve balık üzerine 2018 yılında Karami ve ark. tarafından yapılan çalışmada, üründe sınırlı sayıda mikroplastik kirliliğine rastlansa da konserve sardalya tüketimi ile bir tüketicinin 1 ila 5 mikroplastik ( $90 \mathrm{~g}$ konservede) partikülüne maruz kalacağı bildirilmiştir. Ayrıca çalışmada izole edilen parçacıkların civa ve kurşun gibi ağır metaller içerdiği de bildirilerek, riskin sadece mikroplastik içeriği ile kalmayacağı ve daha detaylı bir araştırmaya ihtiyaç olduğu vurgulanmıştır. Bununla birlikte tüketicilerin tek bir kaynaktan değil pek çok kaynaktan mikroplastiğe maruz kaldığı ve çoklu mikroplastik maruziyetinin insanlar için potansiyel bir sağlık tehlikesi oluşturacağı düşünülmektedir.

\section{Sonuç}

Yapılan araştırmalar, mikro- ve nano plastiklerin çevrede kalıcı bir kirletici olduğu ve gittikçe artan oranlarda karasal ve sucul ekosistemlerde biriktiğini göstermektedir. Okyanusların, karaların ve sucul sistemlerin mikroplastiklerle kirlenmesi sadece ekolojik bir zarar olarak değerlendirilmemekte, aynı zamanda gıda güvenliği ve bunun sonucu olarak insan sağlığını da tehdit eden bir unsur haline gelmektedir. Yapılmış çalışmalar, özelikle deniz canlılarının yüksek oranda mikroplastiklere maruz kaldığını ortaya koymaktadır. Bununla birlikte, insanlar tarafindan tüketilen gıda maddelerinin de hammadde, üretim aşamaları veya paketleme sirasında kullanılan plastik ambalaj materyallerinden veya ürünün tüketimi esnasında havadan kaynaklanabilecek mikroplastik kontaminasyonuna uğrayabileceği ifade edilmektedir. Bununla birlikte, gida maddelerindeki mikroplastik varlığının belirlenmesine yönelik yapılmış çalışma sayısı oldukça sınırlıdır ve günlük hayatımıza dahil ettiğimiz pek çok plastik materyalin gidalara mikroplastik kontaminasyonuna neden olup olmadığı tam olarak bilinmemektedir. Yapılmış sınırlı sayıdaki çalışmalarda; bal, içme suyu, tuz ve poşet çay gibi farklı tip ve sınıfta gıda maddesinin yüksek düzeylerde mikroplastik içeriğine sahip olabileceği bildirilmiştir. Sonuç olarak, ham ve işlenmiş gıdaların mikroplastik içeriklerinin ve gıda üretim, işleme, ambalajlama ve tüketim koşullarının gıdalarda mikroplastik oluşumuna etkilerinin belirlenmesine yönelik daha fazla çalışmanın yapılması gerekmektedir. Bu çalışmaların, insanların mikroplastiklere maruziyetinin ve mikroplastiklerin insan sağlığ üzerindeki olumsuz etkilerinin ortaya konulmasına yardımcı olacağı düşünülmektedir. 


\section{Kaynakça}

Akbay, İ. K., \& Özdemir, T. (2016). Monomer migration and degradation of polycarbonate via UV-C irradiation within aquatic and atmospheric environments. Journal of Macromolecular Science, Part A, 53(6), 340-345.

Alimba, C. G., \& Faggio, C. (2019). Microplastics in the marine environment: Current trends in environmental pollution and mechanisms of toxicological profile. Environmental Toxicology and Pharmacology, 68, 61-74.

Andrady, A. L. (2017). The plastic in microplastics: A review. Marine Pollution Bulletin, 119(1), 12-22.

Aslan, R. (2018). Mikroplastikler: Hayatı Kuşatan Yeni Tehlike. Ayrıntı Dergisi, 6(66).

Aydın, S., Muhammed, Ulvi, M., Aydın, M. E., Ulvi, A. (2019). Mikroplastikler ve Çevresel Etkileri. 4. Uluslararası Bilimsel Araştırmalar Kongresi, 14-17 Şubat 2019, Yalova, 17-26.

Baalkhuyur, F. M., Dohaish, E. J. A. B., Elhalwagy, M. E., Alikunhi, N. M., AlSuwailem, A. M., Rostad, A., Coker, D. J., Berumen, M. L., \& Duarte, C. M. (2018). Microplastic in the gastrointestinal tract of fishes along the Saudi Arabian Red Sea coast. Marine Pollution Bulletin, 131, 407-415.

Barnes, D. K., Galgani, F., Thompson, R. C., \& Barlaz, M. (2009). Accumulation and fragmentation of plastic debris in global environments. Philosophical Transactions of the Royal Society B: Biological Sciences, 364(1526), 1985-1998.

Bellas, J., Martínez-Armental, J., Martínez-Cámara, A., Besada, V., \& Martínez-Gómez, C. (2016). Ingestion of microplastics by demersal fish from the Spanish Atlantic and Mediterranean coasts. Marine Pollution Bulletin, 109(1), 5560 .

Botterell, Z. L., Beaumont, N., Dorrington, T., Steinke, M., Thompson, R. C., \& Lindeque, P. K. (2019). Bioavailability and effects of microplastics on marine zooplankton: A review. Environmental Pollution, 245, 98-110.

Carbery, M., O'Connor, W., \& Palanisami, T. (2018). Trophic transfer of microplastics and mixed contaminants in the marine food web and implications for human health. Environment International, 115, 400-409.

Enrique De-la-Torre, G. (2019). Microplastics: an emerging threat to food security and human health. Journal of Food Sclence and Technology-Mysore. 1-8.

EFSA Panel on Contaminants in the Food Chain (CONTAM). (2016). Presence of microplastics and nanoplastics in food, with particular focus on seafood. Efsa Journal, 14(6), e04501.

Eriksen, M., Mason, S., Wilson, S., Box, C., Zellers, A., Edwards, W., Farley, H. \& Amato, S. (2013). Microplastic pollution in the surface waters of the Laurentian Great Lakes. Marine pollution bulletin, 77(1-2), 177-182.

Esmeray, E., Armutcu, C. Mikroplastikler, Çevre Ve İnsan Sağlı̆̆1 Üzerine Etkileri Ve Analiz Yöntemleri. Düzce Üniversitesi Bilim ve Teknoloji Dergisi, 8(1), 839-868.

Fonseca, M. M. A., Gamarro, E. G., Toppe, J., Bahri, T., \& Barg, U. (2017). The Impact of Microplastics on Food Safety: the Case of Fishery and Aquaculture Products. FAO Aquaculture Newsletter, (57), 43-45.

Gesamp. (2016). Sources, fate and effects of microplastics in the marine environment: part two of a global assessment. IMO/FAO/UNESCO-

IOC/UNIDO/WMO/IAEA/UN/UNEP/UNDP Joint Group of Experts on the Scientific Aspects of Marine Environmental Protection, 220.
Gündoğdu, S. (2018). Contamination of table salts from Turkey with microplastics. Food Additives \& Contaminants: Part A, 35(5), 1006-1014.

Gündoğdu, S., Çevik, C., \& Ataş, N. T. (2020). Stuffed with microplastics: Microplastic occurrence in traditional stuffed mussels sold in the Turkish market. Food Bioscience, 100715.

Hernandez, L. M., Xu, E. G., Larsson, H. C., Tahara, R., Maisuria, V. B., \& Tufenkji, N. (2019). Plastic teabags release billions of microparticles and nanoparticles into tea. Environmental Science \& Technology, 53(21), 12300-12310.

Hesler, M., Aengenheister, L., Ellinger, B., Drexel, R., Straskraba, S., Jost, C., Wagner, S., Meier, F., von Briesen, H., Buchel, C., Wick, P., Buerki-Thurnherr, T., \&Kohl., Y. (2019). Multiendpoint toxicological assessment of polystyrene nano-and microparticles in different biological models in vitro. Toxicology in Vitro, 61, 104610.

Iñiguez, M. E., Conesa, J. A., \& Fullana, A. (2017). Microplastics in Spanish table salt. Scientific Reports, 7(1), 1-7.

Johnson, N. G., Burnett, L. E., \& Burnett, K. G. (2011). Properties of bacteria that trigger hemocytopenia in the Atlantic blue crab, Callinectes sapidus. The Biological Bulletin, 221(2), 164-175.

Karami, A., Golieskardi, A., Choo, C. K., Larat, V., Karbalaei, S., \& Salamatinia, B. (2018). Microplastic and mesoplastic contamination in canned sardines and sprats. Science of the Total Environment, 612, 1380-1386.

Käppler, R, A., Fischer, D., Oberbeckmann, S., Schernewski, G., Labrenz, M., Eichhorn, K. J., \& Voit, B.( 2016). Analysis of environmental microplastics by vibrational microspectroscopy: FTIR, Raman or both? Analytical and bioanalytical chemistry, 408(29), 8377-8391.

Kedzıerskı, M., Lechat, B., Sire, O., Le Maguer, G., Le Tilly, V., \& Bruzaud, S. (2020). Microplastic contamination of packaged meat: Occurrence and associated risks. Food Packaging and Shelf Life, 24, 100489.

Kutralam-Muniasamy, G., Pérez-Guevara, F., Elizalde-Martínez, I., \& Shruti, V. C. (2020). Branded milks-Are they immune from microplastics contamination? Science of The Total Environment, 714, 136823.

Kühn, S., van Franeker, J. A., O’donoghue, A. M., Swiers, A., Starkenburg, M., van Werven, B., Foekema, E., Hermsen, E., Egelkraut-Holtus, M., \& Lindeboom, H. (2020). Details of plastic ingestion and fibre contamination in North Sea fishes. Environmental Pollution, 257, 113569.

Kosuth, M., Mason, S. A., \& Wattenberg, E. V. (2018). Anthropogenic contamination of tap water, beer, and sea salt. PloS one, 13(4), 1-18.

Li, J., Yang, D., Li, L., Jabeen, K., \& Shi, H. (2015). Microplastics in commercial bivalves from China. Environmental Pollution, 207, 190-195.

Liebezeit, G., \& Liebezeit, E. (2013). Non-pollen particulates in honey and sugar. Food Additives \& Contaminants: Part A, 30(12), 2136-2140.

Liebezeit, G., \& Liebezeit, E. (2014). Synthetic particles as contaminants in German beers. Food Additives \& Contaminants: Part A, 31(9), 1574-1578.

Lusher, A., Hollman, P., \& Mendoza-Hill, J. (2017). Microplastics in fisheries and aquaculture: status of knowledge on their occurrence and implications for aquatic organisms and food safety. FAO Fisheries and Aquaculture Technical Paper, (615). 
Lwanga, E. H., Vega, J. M., Quej, V. K., de los Angeles Chi, J., del Cid, L. S., Chi, C., Segura, G. E., Gertsen, H., Salanki, T., van der Ploeg, M., Koelmans, A. A., \& Geissen, V. (2017). Field evidence for transfer of plastic debris along a terrestrial food chain. Scientific Reports, 7(1), 1-7.

Mühlschlegel, P., Hauk, A., Walter, U., \& Sieber, R. (2017). Lack of evidence for microplastic contamination in honey. Food Additives \& Contaminants: Part A, 34(11), 1982-1989.

Opmaan, B. E., Sarau, G., Holtmannspötter, H., Pischetsrieder, M., Christiansen, S. H., Dicke, W. (2018). Small-sized microplastics and pigmented particles in bottled mineral water. Water research, 141, 307-316.

Öztürk, M. (2005). Daha iyi bir çevre için plastikleri geri kazanalım. Erişim adresi: http://www.pagev.org.tr/admin/pics/dosyalar/plastik_geri_ka zanim.pdf

Peixoto, D., Pinheiro, C., Amorim, J., Oliva-Teles, L., Guilhermino, L., \& Vieira, M. N. (2019). Microplastic pollution in commercial salt for human consumption: A review. Estuarine, Coastal and Shelf Science, 219, 161-168.

Rist, S., Almroth, B. C., Hartmann, N. B., \& Karlsson, T. M. (2018). A critical perspective on early communications concerning human health aspects of microplastics. Science of the Total Environment, 626, 720-726.

Rustagi, N., Pradhan, S. K., \& Singh, R. (2011). Public health impact of plastics: An overview. Indian Journal of Occupational and Environmental Medicine, 15(3), 100.

Schymanski, D., Goldbeck, C., Humpf, H. U., \& Fürst, P. (2018). Analysis of microplastics in water by micro-Raman spectroscopy: release of plastic particles from different packaging into mineral water. Water Research, 129, 154-162.

Shim, W. J., Hong, S. H., \& Eo, S. E. ( 2017). Identification methods in microplastic analysis: a review. Analytical Methods, 9(9), 1384-1391.

Shruti, V. C., Peréz-Guevara, F., Elizalde-Martínez, I., \& Kutralam-Muniasamy, G. (2020). First study of its kind on the microplastic contamination of soft drinks, cold tea and energy drinks - Future research and environmental considerations. Science of The Total Environment, 138580.

Sjollema, S. B., Redondo-Hasselerharm, P., Leslie, H. A., Kraak, M. H., \& Vethaak, A. D. (2016). Do plastic particles affect microalgal photosynthesis and growth? Aquatic Toxicology, 170, 259-261.

Smith, M., Love, D. C., Rochman, C. M., \& Neff, R. A. (2018). Microplastics in seafood and the implications for human health. Current Environmental Health Reports, 5(3), 375386.

Stock, V., Fahrenson, C., Thuenemann, A., Dönmez, M. H., Voss, L., Böhmert, L., Braeuning, A., Lampen, A., \& Sieg, H. (2020). Impact of artificial digestion on the sizes and shapes of microplastic particles. Food and Chemical Toxicology, 135, 111010.

Türk Gida Kodeksi Gıda ile Temas Eden Plastik Madde ve Malzemeler Tebliği. (2019). Resmi Gazete. (Say1: 30989(Mükerrer). Erişim Adresi: https://www.resmigazete.gov.tr/eskiler/2019/12/20191225M 1-10.htm

Toussaint, B., Raffael, B., Angers-Loustau, A., Gilliland, D., Kestens, V., Petrillo, M., Rio-Echevarria, I. M., \& Van den Eede, G. (2019). Review of micro-and nanoplastic contamination in the food chain. Food Additives \& Contaminants: Part A, 36(5), 639-673.
Tsiropoulos, I., Faaij, A. P., Lundquist, L., Schenker, U., Briois, J. F., \& Patel, M. K. (2015). Life cycle impact assessment of bio-based plastics from sugarcane ethanol. Journal of Cleaner Production, 90, 114-127.

Van Cauwenberghe, L., \& Janssen, C. R. (2014). Microplastics in bivalves cultured for human consumption. Environmental Pollution, 193, 65-70.

Van Raamsdonk, L. W., van der Zande, M., Koelmans, A. A., Hoogenboom, R. L., Peters, R. J., Groot, M. J., Peijnenburg., A. C. M., \& Weesepoel, Y. J. (2020). Current Insights into Monitoring, Bioaccumulation, and Potential Health Effects of Microplastics Present in the Food Chain. Foods, 9(1), 72.

Waring, R. H., Harris, R. M., \& Mitchell, S. C. (2018). Plastic contamination of the food chain: A threat to human health? Maturitas, 115, 64-68.

Welle, F., \& Franz, R. (2018). Microplastic in bottled natural mineral water-literature review and considerations on exposure and risk assessment. Food Additives \& Contaminants: Part A, 35(12), 2482-2492.

Wilcox, C., Van Sebille, E., \& Hardesty, B. D. (2015). Threat of plastic pollution to seabirds is global, pervasive, and increasing. Proceedings of the National Academy of Sciences, 112(38), 11899-11904.

Yates, J., Deeney, M., White, H., Joy, E., Kalamatianou, S., \& Kadiyala, S. (2019). PROTOCOL: Plastics in the food system: Human health, economic and environmental impacts. A scoping review. Campbell Systematic Reviews, 15(1-2).

Yildiztekin, K. G., Erkekoğlu, P., \& Koçer-Gümüşel, B. (2017). Plastikler Sağlık İçin Bir Tehdit mi? Ftalatlara Genel Bir Bakış. FABAD Journal of Pharmaceutical Sciences, 42(2), 111.

Yurtsever, M. Nano-ve Mikroplastik'lerin İnsan Sağlığı ve Ekosistem Üzerindeki Olası Etkileri. Menba Kastamonu Üniversitesi Su Ürünleri Fakültesi Dergisi, 5(2), 17-24.

Yurtsever, M. (2015). Mikroplastikler'e Genel Bir Bakış. Dokuz Eylül Üniversitesi Mühendislik Fakültesi Fen ve Mühendislik Dergisi, 17(50), 68-83.

Yurtsever, M. (2018). Microplastic pollution threat in table salt that an abiotic sea product. Ege Journal of Fisheries and Aquatic Sciences, 35(3), 243-249

Zhang, F., Wang, X., Xu, J., Zhu, L., Peng, G., Xu, P., \& Li, D. (2019). Food-web transfer of microplastics between wild caught fish and crustaceans in East China Sea. Marine Pollution Bulletin, 146, 173-182. 